\title{
30 PROMOTING TRADING PARTNER TRUST IN B2B E-COMMERCE THROUGH THE USE OF SERVICE LEVEL AGREEMENTS AND THE ESTABLISHMENT OF SUPPORT CENTRES
}

\author{
Ioannis Ignatiadis, Konstantinos Tarabanis \\ Centre for Research and Technology Hellas-Informatics and Telematics Institute \\ 1st Km Thermi-Panorama Road, Thermi-Thessaloniki, GR-57001 GREECE \\ iignat@uom.gr, kat@.uom.gr
}

\begin{abstract}
The purpose of this paper is to propose ways to increase the people-side trust in business-to-business e-commerce environments. In particular, two mechanisms are proposed: (A) The use of Service Level Agreements, a special form of contract popular in the IT industry, which can be introduced to cover all legal and non-legal requirements of online trading. (B) The establishment of Support Centres, which can act as intermediaries, and which can guarantee the trustworthiness of companies.

From a practical research perspective, the work within the framework of the $E U$ - co-funded project "LAURA" is presented. The goal of this project is to set-up adaptive zones of B2B electronic commerce for Small and Medium Enterprises (SMEs) from the Less Favoured Regions of Europe.
\end{abstract}

\section{INTRODUCTION}

Technological threats arising from the use of Business-to-Business e-commerce are being addressed by designing even more robust and secure information systems that are more resilient to misuse and external attacks. However, there still remains the people-side trust as a barrier for implementing e-commerce processes. Although many mechanisms like digital signatures [Gerwick (2000), Balacheff et al (2002)], trusted third parties [Janssen and Sol (2000)], establishment of codes of conduct [Healy and Iles (2001)], rating systems [Chen and Singh (2001), Dellarocas (2000), Dellarocas (2001)] etc, have been implemented to reduce this degree of uncertainty regarding a company's trading partners in e-commerce, the issue of trust for many companies is still open.

The purpose of this paper is to suggest further, complimentary ways of increasing the trading partner trust in a B2B e-commerce environment. This involves the use of Service Level Agreements (SLAs) for specifying the trading partner 
arrangements between two companies, not from a technological, but from a business point of view. In addition, the establishment of Support Centres that can act as Trusted Third Parties, and which can intervene in case of dispute, can also further increase trading partner trust.

The rest of this paper is organised as follows: Section 2 presents a literature review of issues regarding trading partner trust and service level agreements. As the concept of Support Centres for B2B e-commerce is very innovative at the time of writing of this paper and no literature on the subject exists, no literature review is shown for the subject of Support Centres. Section 3 presents the suggestion of this paper for the use of Service Level Agreements and Support Centres in order to increase the degree of trust between trading partners in a B2B e-commerce environment. In Section 4, the work of the IST project "LAURA" from a practical perspective is presented, which proposes to introduce Service Level Agreements and Support Centres in a B2B environment. Section 5 suggests some future research work.

\section{LITERATURE REVIEW}

\subsection{Trading Partner Trust}

Gambetta (1990) defines trust as “...trust (or, symmetrically, distrust) is a particular level of the subjective probability with which an agent will perform a particular action, both before [we] can monitor such action (or independently of his capacity of ever to be able to monitor it) and in a context in which it affects [our] own action..."

With regards to the above statement, Abdul-Rahman \& Hailes (1998) mention that of importance are the three points made in that definition of trust:

1. That trust is subjective

2. Trust is affected by those actions that we cannot monitor

3. The level of trust depends on how our own actions are in turn affected by the agent's actions

Shneiderman (2000) gives an alternative definition of trust, which is that "...[Trust is] the positive expectation a person has for another person or an organization based on past performance and truthful guarantees. Trust is about expectations of the future. It accrues to individuals and organizations due to their previous good works and clear promises. It implies responsibility for behaviour and willingness to make good for failures. It is stronger that reliance, due to the responsibility and guarantee that only people and organizations can offer..."

In the context of this paper, we prefer the 2 nd definition of trust, that of Shneiderman (2000). His definition fits better our proposal for increasing trading partner trust based on the use of Service Level Agreements and Support Centres. As will be shown later in this paper, Service Level Agreements can be used to specify service level guarantees and penalties for non-compliance to contract clauses. SLAs can also be monitored to determine past performance of a particular trading partner. This can increase expectations about future performance for that particular trading partner, and hence increase the overall trust between trading partners.

Regarding the trust mechanisms between people or organizations, Chadwick (2001) mentions that "...We tend to trust other people and the organizations they 
represent when (a) our actions and theirs are interdependent, (b) they behave predictably given the situation, (c) the decision to trust fits the situation, and (d) not displaying trust would seem to go against the present business relationship..."

Trust between trading partners is a very important ingredient for participation in an e-commerce platform. Many authors have pointed out this, in particular the barriers to online trust in an e-commerce environment, arising from the lack of faceto-face contact [Healy and Iles (2001), Chadwick (2001), Ratnasingham and Kumar (2000), Ba, Whinston and Zhang (1999)].

Characteristically, Ba, Whinston and Zhang (1999) argue that" “... In a traditional face-to-face business environment, eye contact, a handshake, and chatting help develop basic trust between vendors and customers. Customers get to know the quality of products by looking, touching and feeling. However, such an interpersonal realm does not exist in the electronic market..."

Chadwick (2001) agrees by saying that "...Several phenomena are absent from e-commerce interactions compared with face-to-face interactions: The presumption of desired relational development is not present, the degree of intimacy in an ecommerce relationship is constrained, and the expansion of whatever e-relationship exists into other domains is limited, if even possible..."

\subsection{Service Level Agreements}

Lee and Ben-Natan (2002) define a Service Level Agreement as “... (In its most basic form), a Service Level Agreement is a contract or agreement that formalises a business relationship, or part of the relationship, between two parties. Most often it takes the form of a negotiated contract between a service provider and a customer and defines a price paid in exchange for an entitlement to a product or service to be delivered under certain terms, conditions, and with certain financial guarantees..."

SLAs are primarily used in the provision of Information Technology (IT) services industry, in order to provide guarantees regarding the level of IT services to be provided. In fact, as Lee and Ben-Natan (2002) mention: “... Service Level Agreements emerged in the early 1990s as a way for Information Technology (IT) departments and service providers within private (usually corporate) computer networking environments to measure and manage the Quality of Service (QoS) they were delivering to their internal customers. Service Level Agreements are the contractual component of QoS and are usually implemented as part of a larger Service Level Management (SLM) initiative..."

In this paper however, we propose to extend the use of SLAs from the IT services industry, and include them as the method of defining the contractual requirements between two general trading partners in a B2B e-commerce environment. In this case the parameters to be measured are not technical like network uptime, data rate etc, but rather the quality of products or services that are to be traded in the e-commerce platform. Those of course vary according to the industrial sector that companies belong to, and the actual products or services that are to be traded.

The main components of a (paper-written) Service Level Agreement are as follows [Sturm, Morris and Jander (2000), Lee and Ben-Natan (2002), Muller (1999)]: 
- Background. Contains information to acquaint a non-technical reader with the application.

- Parties to the agreement. Mainly the provider of the service and the consumer (client).

- Service Level Metrics. The agreed-upon levels of service that are to be provided. Every Service Level Metric must be measured.

- Timeliness. Provides a qualitative measure in order to let clients know how fast they can expect the services to be provided to them.

- Availability. Specifies when the required service will be available to clients.

- Limitations. Describes the limitations of the service to be provided, for example during non-office hours.

- Compensation. Includes penalties the service provider incurs for poor performance, as well as rewards obtained from the client in case of satisfactory performance.

- Optional Services. It is wise to include a provision for extra options in the agreement, if the client might want some of these.

- Measurement. Describes the process by which actual service levels will be monitored and compared with the agreed upon service levels, as well as the frequency of monitoring.

- Reporting. The reports generated for the SLAs are key components of the SLA process.

- Re-negotiation. Describes how and under what circumstances the SLA can be changed to reflect changes in the environment.

- Approvals. Involves the final agreement on the SLA details by both parties, and the signing of it.

\section{PROMOTING TRADING PARTNER TRUST}

The actual proposal of this paper as will be shown later is to enhance trading partner trust in a B2B environment with the use of Service Level Agreements for specifying contracting requirements between trading partners. Setting-up Support Centres that provide guidance and advice regarding e-commerce, can also further increase trading partner trust.

In a B2B e-commerce context, the main questions regarding trust arise from the buyer's as well as from the seller's point of view.

From the buyer's point of view the main questions arising in regards to the products / services to be bought are as follows:

- Will the price be the one quoted?

- Will the products/services be delivered within the promised timeframes?

- Will the product quality be the one expected?

- Will guarantees be offered in case the product breaks down, does not perform satisfactorily, or is of insufficient quality? (similarly for services)

From the seller's point of view the main questions arising in regards to the products / services to be sold are as follows:

- Is the client trustworthy enough to pay for the goods / services ordered?

- Does the client have a history of bad payments?

- Can the client pay on time? 
- Are there guarantees (interest, etc) for late payments?

Most of the above issues can be specified in a Service Level Agreement. In addition, past performance of trading partners, as this is reflected by monitoring the relevant SLAs, can also help increase the degree of trust between trading partners.

The business setup in a B2B environment for which the SLAs are intended can actually vary. It can be an open platform where companies can trade (buy or sell) their goods, or it can be a virtual enterprise setting where partners are known to each other. However, especially in the former case (open platform), it is a necessary condition that companies register with their local Support Centre (acting as Trusted Third Party), which can ensure that the company actually exists and is trustworthy. In the latter case (virtual enterprise) where companies already know each other, registering with a Support Centre is not a mandatory condition, but can certainly help increase trust between participating companies.

We therefore posit that in order to increase the level of trust between trading partners in a B2B e-commerce environment, the following conditions must be met:

- Before entering the e-commerce platform, every company must be scrutinized by a Trusted Third Party for its credentials, trustworthiness and financial history. Only then can the company be given a username and password to use the system.

- To harmonize and facilitate the writing of a Service Level Agreement between trading partners, a template must exist which will list the areas that must be covered in the SLA.

- The legal disclaimers regarding the validity and legal status of the SLA must be fixed and must reflect the current laws of the country in which the SLA will be signed. For international contracts, the relevant international laws must be mentioned.

- SLAs agreed between trading partners must reside in electronic form in a local repository, and be easily accessible in case of disputes.

- The performance of an SLA must be available for monitoring, and the results must be available for distribution to the interested parties.

- In case of dispute regarding the clauses of an SLA, a Trusted Third Party (TTP) must exist that will resolve the issue.

- After its completion, the performance of a trading partner according to what was defined in the SLA must be judged upon by the other trading partner. A rating system must exist for this, which will determine the relevant performance of trading partners.

Due to space restrictions that are posed on a conference paper, the above issues will not be analyzed any further, however, those will be discussed from a practical perspective in the section that follows.

\section{TRADING PARTNER TRUST IN PRACTICE}

This section describes the ideas of this paper from a practical perspective, using the LAURA project as a vehicle. A full description of the LAURA project can be found in its official website, www.lauraproject.org.

The LAURA project will initially run on 4 Less Favoured Regions (LFRs) of Europe: Messinia and Epirus (Greece), South-Central Region (Bulgaria) and 
Saxony-Anhalt (Germany). Especially in the regions of Greece and Bulgaria, companies (SMEs) are rather isolated in their trading, with most of it being done with other local companies. There is very little or none international trade for those companies.

In addition, the degree of familiarity of those companies with e-commerce issues is rather small, and participation in an e-commerce site is rather rare. As a consequence, there is a great deal of mistrust and unawareness of e-commerce processes.

In the initial phase of the project, seminars and training sessions will help reduce the initial fears about e-commerce. In the running phase of the project, various methods will be used to promote trust between trading partners:

- The Support Centres that will be established in each region will act as Trusted Third Parties for the trading activities between business partners. They will also act as mediators in cases of dispute.

- Prior to their entry into the system, companies will be thoroughly examined for their credibility and financial robustness.

In particular relating to the issue of using Service Level Agreements as a method to enhance the trading partner trust, the following must be noted:

- The Support Centre in each region will provide SLA templates for the case of intra-regional trading between companies in a particular region. In the case of interregional or international trading, SLA templates will be agreed between the relevant Support Centres.

- The legal validity of SLAs will be ensured by the Support Centres and will follow the current national or international laws.

Having ensured the above preconditions, in the daily trading of companies, SLAs will play a crucial role in promoting the level of trust between trading partners.

Each SLA will describe the rights and obligations of each partner (customer and seller). Those will include the description and quantity of the products to be traded, method of payment (bank, credit card etc), date and amount of payments to be made, shipping instructions, etc.

In addition, SLAs will contain some quality criteria for the products to be traded, and compensations (financial or otherwise) to be provided in case quality levels fall below the standards specified in the SLA.

The quality criteria will of course depend on the sector where the trading takes place. For example, in the food sector, quality criteria can relate to national or international regulations about food hygiene, environmental standards under DIN EN ISO 14001, biological product certificates, quality standards under DIN EN ISO 9000ff, etc.

To increase the trading partner reputation, and consequently trust, a rating module will be implemented in the LAURA system, which will enable trading partners to judge each other's performance with respect to the issues specified in the SLA. This is in a sense similar to the rankings given in auction sites, like for example ebay (www.ebay.com).

In this sense, a customer can give a positive feedback for a supplier if he/she received the products / services within the time specified in the SLA, and with the specified quality and quantity.

A supplier can then give a positive feedback for a customer, if he/she received his/her payment on time, and in the form specified in the SLA. 
The system can then aggregately rank each individual partner according to the ratings received. The trustworthiness of this rating system of course depends on the companies providing the feedback giving a true picture of the performance of other trading partners according to the relevant Service Level Agreements. It also depends on a company providing feedback being the one it claims to be, and not using another false identity.

However, the above issues can be solved with the help of Support Centres as Trusted Third Parties. In case a trading partner receives a feedback rating which it thinks is unfair and does damage to its reputation, it can contact its regional Support Centre to clarify the issue. The Support Centre in this case can examine the relevant SLA in its local repository to determine whether the rating received was fair or not. Fake identities can also be dealt with, by carefully scrutinizing companies before allowing them to use the system, and personally contacting them in case of an alleged fake identity.

SLAs can also be a point for negotiation and differentiation between trading partners. A trading partner which specifies bigger guarantees and is willing to pay bigger compensation for non-performance than another trading partner, has a potentially better selling point as specified in the proposed SLA.

Apart from the ratings of the trading partners according to SLA performance, trust can also be increased by the fact that when an SLA is agreed between two trading partners (by signing it electronically or otherwise), this then becomes a legally valid document. Trust is enhanced by the fact that the SLA can be referred to in case of a legal dispute.

The role of the Support Centres in this case is quite crucial in the sense that they provide a central repository where all SLAs are held and can be recalled in case of a dispute.

Regarding the actual system to be used as the e-commerce platform, this also plays quite an important role in determining level of use, and consequently trust, between companies. Therefore, continuous contact with the end users throughout the design and development stages of the system ensures that it matches their requirements.

At the time of writing of this paper, the design and implementation of the LAURA system that is to support B2B e-commerce trading between companies, is at its final stages. As such, companies have not yet used the system for trading activities, and therefore practical results regarding the level of trust between companies are not yet available.

In order to measure the success of the proposed solution for increasing trading partner trust in the LAURA project, companies using the system will be approached via face-to-face interviews or questionnaires, after the successful completion of the project. The purpose of these approaches will be to examine to what extent the fears of companies regarding e-commerce have been alleviated, and to what extent trust has been enabled with the use of Service Level Agreements and the establishment of Support Centres. These approaches will also pinpoint potential problems that may arise by using the system, and hence solutions to overcome these will be developed. 


\section{FUTURE RESEARCH}

The research challenge from a business point of view is to determine the quality criteria in a SLA between trading partners in a B2B environment. This of course largely depends on the sector where companies come from, and the actual products / services that are to be traded in the e-commerce platform.

From a technical point of view, the research challenge would be to automatically monitor Service Level Agreements in a B2B environment, for determination of nonconformance. This would lead to an automatic (and possibly more accurate) rating of the performance of trading partners as this is reflected in the relevant SLAs.

\section{REFERENCES}

1. Abdul-Rahman Alfarez, Hailes Stephen, “A Distributed Trust Model”, ACM, 1998

2. Ba Sulin, Whinston Andrew B, Zhang Hang, "Building Trust in the Electronic Market through an Economic Incentive Mechanism”, ACM, International Conference on Information Systems, 1999

3. Balacheff Boris, Chen Liqun, Plaquin David, Proudler Graeme, "A Trusted Process to Digitally Sign a Document", NSPW'01, September 1-13 2002, Cloudcroft, New Mexico, USA

4. Chadwick SA, "Communicating Trust in E-Commerce Interactions", Management Communication Quarterly, Vol. 14, No. 4, May 2001, pp. 653-658

5. Chen Mao, Singh Jaswinder Pal, "Computing and using Reputations for Internet Ratings", EC'01, October 14-17 2001, Tampa, Florida, USA

6. Dellarocas Chrysanthos, "Immunizing Online Reputation Reporting Systems against unfair Ratings and Discriminatory Behaviour', EC'00, October 17-20, 2000, Minneapolis, Minnesota

7. Dellarocas Chrysanthos, "Analyzing the Economic Efficiency of eBay-like Online Reputation Reporting Mechanisms”, EC'01, October 14-17 2001, Tampa, Florida, USA

8. Gambetta Diego, "Can we trust Trust?", in "Trust: Making and Breaking Cooperative Relations", Gambetta, D (ed.), Basil Blackwell, Oxford, 1990, pp. 213-237

9. Gerwick Kate, "Will the digital signature transform e-commerce?", ACM Digital Library, Business: the 8th Layer, September 2000

10. Healy Mike, Jennifer Iles, "Ethical aspects of e-business: the use of codes of conduct", Blackwell Publishers, Vol. 10, No. 3, July 2001

11. Janssen Marijn, Sol Henk G, "Evaluating the role of intermediaries in the electronic value chain", Internet Research: Electronic Networking Applications and Policy, Volume 10, Number 5, pp. 406-417

12. Kim J, Moon JY, "Designing towards emotional usability in customer interfaces - Trustworthiness of cyber-banking system interfaces", Interacting with Computers, 1998,Vol. 10, pp. 1-29

13. LAURA Project, "LAURA project on the net", http://www.lauraproject.org, IST Project 2001-33251, 2003

14. Lee John J, Ben-Natan Ron, "Integrating Service Level Agreements: Optimising your OSS for SLA Delivery", Wiley, 2002

15. Muller Nathan J, "Managing Service Level Agreements", International Journal of Network Management, Vol. 9, pp. 155-166, 1999

16. Ratnasingham Pauline, Kumar Kuldeep, "Trading Partner Trust in Electronic Commerce Participation", ACM, International Conference on Information Systems, 2000

17. Shneiderman Ben, "Designing Trust into Online Experiences", Communications of the ACM, Vol. 43, No. 12, December 2000

18. Sturm Rick, Morris Wayne, Jander Mary, "Foundations of Service Level Management", SAMS, 2000 